\title{
Survey of Public Knowledge Level on the Efficacy of Alcohol-Based Hand Sanitizers
}

\section{Peter Zhong Hao Lu' ${ }^{1}$, Helen Heacock ${ }^{2}$}

1. Lead Author, B. Tech Student, School of Health Sciences, British Columbia Institute of Technology, 3700 Willingdon Ave, Burnaby, BC, V5G 3H2

2. Supervisor, School of Health Sciences, British Columbia Institute of Technology, 3700 Willingdon Ave, Burnaby, BC, V5G 3H2

\begin{abstract}
:
Introduction: Alcohol-based hand sanitizers have received wide-spread acceptance in many institutions as a form of disinfection. Whether the public truly understands the mode of action of these products and what they are effective and not effective against has not been examined. The goal of this paper is to test the public's knowledge regarding alcohol-based hand sanitizers and examine if there are any demographic variables that may contribute to differences in knowledge level.
\end{abstract}

Methods: An online survey was created via Survey Monkey and distributed through Facebook, a social media platform. A paper copy of the survey was distributed to participating senior homes in the Lower Mainland. The knowledge scores were analyzed using Microsoft Excel and NCSS to evaluate whether knowledge scores are affected by demographic variables. Incentives such as water bottles and tumblers were used to invite participants to take part in the survey.

Results: The knowledge scores from respondents in health-related professions did not differ significantly from respondents in non-health related professions, however both groups differed from those that are not employed $(\mathrm{P}=0.000060)$. Differences in ethnicity did not result in a significantly different knowledge scores regarding hand sanitizers ( $\mathrm{P}=0.441511$ ). Respondents who are over the age of 40 (particularly those who are 70 and above) and respondents whose level of education was high school graduation or less lacked knowledge regarding hand sanitizers compared to other demographic groups. The majority of the respondents knew ABHS was effective against influenza virus. Nearly half of the respondents erroneously thought ABHS was effective against Norovirus.

Conclusion: Government agencies and public health officials should focus educational efforts on the population who are over the age of 40, particularly the senior population, and whose level of education is high school or less.

Key words: Public knowledge; alcohol-based hand sanitizers; occupation; education; gender; age; culture; religion; ethnicity

\section{INTRODUCTION}

Alcohol-based hand sanitizers (ABHSs) can be found at educational institutions, work locations, recreation centres, doctors' office, hospitals, long term care facilities, and even daycares. They have been proven to be effective in preventing infectious diseases by reducing the count of harmful disease-causing micro-organisms (pathogens) on users' hands. This paper provides a brief introduction to ABHSs including: why they are so popular, their application, the antimicrobial actions of ABHSs, their limitations, and how they compare with soap and water.

\section{LITERATURE REVIEW}

\section{Background on hand hygiene}

Ignaz Semmelweis (1818-1865) was a pioneer in promoting the importance of proper hand 
hygiene. He noticed the rates of peripartum mortality in hospitals were much higher than the rates of peripartum mortality where midwives were the primary care provider. As a result of this observation, he made handwashing with soap as a mandatory measure prior to care for women in labor, thereby drastically reducing the number of deaths (Widmer, 2000). For gastrointestinal, respiratory tract, and skin infections in the home, the hands are the most important bridge between pathogens and portal of entry such as the mouth, nose, and the eyes (Bloomfield, Aiello, Cookson, O’Boyle, \& Larson, 2007). The British Columbia Centre for Disease Control (BCCDC) estimates that up to $80 \%$ of infections are spread by the hands. To reduce the likelihood of contracting colds, influenza and other common infections, the BCCDC recommends people to wash their hands at least 5 times a day (BCCDC, 2012). But what happens when soap and water are not readily available, or other factors that lead to poor hand hygiene in health-care setting, get in the way of proper handwashing? This is where the usefulness of alcohol-based hand sanitizers becomes evident.

What is in alcohol-based hand sanitizers? Most of the ABHSs products contain ethyl alcohol (AKA ethanol), isopropyl alcohol (AKA isopropanol or rubbing alcohol), n-propanol, or a combination of them (Li, 2011; Widmer, 2000). In terms of ranking the different effectiveness between the types of alcohols, n-propanol is more effective than iso-propanol which is more effective than ethanol (Rotter, 2001).

\section{When should alcohol-based hand sanitizers be used?}

According to the Ohio Department of Health's factsheet, ABHSs should be used before preparation of food, eating, touching contact lenses, performing first aid, caring for an ill person, or performing a medical procedure. They also state ABHSs should be used after contact with bodily fluids, use of bathroom, changing diapers, touching animals or animal wastes, handling of raw food products, coughing or sneezing into hands, caring for a sick or injured person, handling garbage, and playing outdoors (Ohio Department of Health, n.d.).

Why are they becoming so popular? Unlike antimicrobial soap, ABHSs do not contribute to antibiotic resistance ( $\mathrm{Li}, 2011$; WHO, 2013). In fact, the appropriate use of
ABHSs can prevent the spread of antibioticresistant bacteria such as methicillin-resistant Staphylococcus aureus and vancomycin-resistant enterococci (CDC, 2002; Boyce, 2000). ABHSs are easy and quick to use, especially in situations where soap and water is not readily available. In a busy environment such as healthcare settings where hygiene is of utmost importance, the quick application of ABHSs can be desirable. In terms of accessibility, handwashing basins cannot be as conveniently installed as ABHSs dispensers can, therefore the lack of accessibility can lead to poor handwashing rates. With young children who may not wash their hands thoroughly, the installation of ABHSs dispensers can be more effective and more preferable over soap and water when their hands are not visibly dirty. Recontamination of washed hands is a possibility when someone turns off the faucet with his/her freshly washed hands instead of using paper towel. The water used to rinse one's hands may also be contaminated by a contaminated aerator or growth in the plumbing system. These contamination issues can be largely avoided or solved by using ABHSs.

\section{How does handwashing compare to alcohol-based hand sanitizers?}

Handwashing and ABHSs have different modes of action. Handwashing with soap and water in conjunction with scrubbing removes microorganisms physically, whereas a sanitizer solution works by denaturing the proteins (Boyce, 2000). ABHSs disrupt the bacterial cell membrane, making the membranes lose their structural integrity (Li, 2011; CIPHI, 2008).

Frequent washes with soap and water can cause irritation and dryness. With the addition of moisturizers or emollients, the use of ABHSs result in fewer skin irritations and are faster, cleaner and more convenient to use than soap and water (Li, 2011).

Many researchers argued ABHSs are more effective than handwashing. Laboratory tests have demonstrated ABHSs can lower the levels of Escherichia coli, Staphylococcus aureus, and Serratia marcescens better than plain water and soap (Pickering, Davis, and Boehm, 2011). Rotter states in his report to the Journal of Hospital Infection (2001) that : "When used for hygienic hand disinfection (i.e., health care personnel handwash), which is directed exclusively against transient hand flora, the antimicrobial effect of alcoholic rubs far exceeds 
that of handwashing with both unmedicated and medicated soap". This sentiment is agreed to by Boyce (2000), who said $60 \%$ to $70 \%$ alcohol solution resulted in better reduction in bacterial count than washing with plain soap and water.

\section{How to apply hand sanitizers?}

A minimum of a dime-sized portion should be applied to one palm, then both hands should be rubbed together until every part of the hands and fingers are covered and the ABHSs have evaporated. Bloomfield et al. (2007) states a higher pathogen log reduction can be achieved by using a higher volume of ABHSs. This is supported by a study in the CDC MMWR (2002) that found $1 \mathrm{~mL}$ of alcohol was less effective than $3 \mathrm{~mL}$. This is backed up by a 2003 study from Food Service Technology, as cited by CIPHI (2008), that $3.0 \mathrm{~mL}$ of ABHSs resulted in a significant increase in reduction of resident and transient flora, and $6.0 \mathrm{~mL}$ provided an even greater reduction. Bloomfield et al. (2007) also stated that the longer the contact time between ABHSs and pathogen, the greater the log reduction.

\section{What concentrations are the most effective?}

The concentrations of alcohol are often expressed as percentage of weight $(\% \mathrm{~m} / \mathrm{m})$ or a percentage of volume $(\% \mathrm{v} / \mathrm{v})$ or percentage of weight per volume (\% w/v) (Rotter, 2001). ABHSs must contain between $60-95 \%$ alcohol in order to be effective in killing most germs (Reynolds, Levy, and Walker, 2006). Concentrations $>95 \%$ becomes less effective because the denaturation action of ABHSs requires water. The optimal concentration in dealing with bacteria is $70 \%$ ethanol and the optimal concentration in dealing with viruses is with 95\% ethanol (CIPHI, 2008).

\section{What is ABHSs effective against?}

In-vitro testing has shown that ABHSs are effective against many gram-positive and gramnegative bacteria (Boyce, 2000) such as E. coli, Salmonella, S. aureus and Shigella (Bloomfield et al, 2007), Mycobacterium tuberculosis (Boyce, 2000), fungi, and enveloped viruses - viruses that have a protective coating around them, such as herpes simplex virus, influenza A virus, respiratory syncytial virus, vaccinia virus, and HIV. Hepatitis B and Hepatitis C virus are also killed by $60-70 \%$ alcohol (CDC, 2002). Even though ABHSs have been proven to be effective against many pathogens, they are not effective against all pathogens.

\section{What are ABHSs not effective against?} ABHSs have limited effectiveness against hydrophilic, non-enveloped viruses, especially enteroviruses such as norovirus or rotavirus (Rotter, 2001). Norovirus is the major cause of foodborne illnesses in the United States (CIPHI, 2008). A study conducted by Liu, Yuen, Hsiao, Jaykus and Moe (2010) found that ethanol was only able to reduce norovirus by at most $0.5 \mathrm{log}$ regardless of the concentration of ethanol used. According to Zimmerman (2011), the use of ABHSs instead of soap and water in nursing homes is actually one of the major risk factors for the number of outbreaks observed. Against norovirus, it appears that the best preventative method is handwashing with soap and water.

A recommendation in the MMWR posted by CDC states ABHSs are not effective against protozoa such as Cryptosporidium (CDC, 2007). ABHSs are also not effective against bacterial spores such as C. difficile, which has a reputation of being a nosocomial pathogen affecting 20\% of the inpatients (Jabbar et al., 2010). Rotter (2001) claims that the reason ABHSs is not effective against spores is due to the short application times. The CDC warns alcoholic handwash or hand rubs are not reliable sporicides against Clostridium spp. or Bacillus spp. Handwashing with non-antimicrobial or antimicrobial soap and water is the best way to protect against the spread of $\mathrm{C}$. difficile or $\mathrm{B}$. anthracis-related infections (CDC, 2002).

\section{What problems are associated with the use of ABHSs?}

ABHSs can cause a stinging sensation if the person applying it has cuts or broken skin (WHO, 2013) which may be enough to deter the person from using the product. Other problems associated with ABHSs include the strong smell of alcohol, potential for triggering allergic reactions, and flammability. ABHSs can be poisonous if ingested in large amounts, especially by young children which accounts for the majority of cases of accidental ingestion $(\mathrm{Li}$, 2011). However, it must be noted that the Maryland Poison Center (2007) states even if the typical amount $(2.5 \mathrm{~mL}$ ) dispensed by a pump dispenser is ingested by a young child, it would not pose a major problem. An average 2 year old weighing 30 pounds would need to ingest 4 teaspoonful or 8 pumps of the ABHSs before 
medical aid is required. $\mathrm{Li}$ (2001) states that even though the concerns with regards to children are valid, the use of ABHSs can be safe with supervision and the benefits of using the product outweigh the risks of accidental ingestion.

\section{What are some myths about ABHSs?}

ABHSs are not effective against all types of pathogen; they are not very effective against non-enveloped viruses, protozoa or bacterial spores (CIPHI, 2008). Some may fear the use of alcohol on their skins will dry out their hands; however newer products on the market have emollients embedded in them to prevent such a problem. In fact, nurses who use ABHSs reported less skin irritation and dryness compared to washing with soap and water (WHO, 2013). Some people may think it has residual long lasting effectiveness. This is false because alcohols do not offer substantial residual activity. However the sub-lethal effect of the alcohol does retard the regrowth of bacteria on the skin (CDC, 2002). ABHSs can provide some residual effect if chlorhexidine, quaternary ammonium compounds, octenidine, or triclosan are incorporated into the formulation (CDC, 2002). It is a common misconception that a person's hands should be washed after the $4^{\text {th }}$ or $5^{\text {th }}$ application of ABHSs. The WHO claims there is not scientific reasoning behind this other than personal preference (WHO, 2013). Some people may think ABHSs will be absorbed into the body and cause intoxication. Studies have shown that the alcohol level found in the blood due to skin absorption is insignificant or undetectable (WHO, 2013). With the benefits and deterrents of using ABHSs already discussed, this literature review will examine if the use or non-use of ABHSs are associated with variables such as educational level, age, gender, religion, or ethnicity.

\section{Role of education level in hand hygiene compliance}

In a survey of 994 American college students, the top 5 reasons for not handwashing were "forget (63\%), too busy (52\%), unnecessary (37\%), soap not in a convenient location (31\%), and no soap available (26\%)" (Scott \& Vanick, 2007). Scott and Vanick suggest that even though well-educated college students recognized the need for proper hand hygiene, behaviour does not always follow suit. This result would seem to suggest that hand hygiene reminders and convenience is more important than educational level. If this result holds true for this ABHSs study, one would expect there would be no differences in the number of times a person would use ABHSs despite differences in education level.

\section{Role of age in hand hygiene compliance} In a study conducted by Whitby, McLaws, and Ross (2006), children aged nine to ten knew handwashing with soap was important in protecting themselves from harmful bacteria and whether or not they wash their hands is influenced by how their hands looked. When mothers were interviewed, they recognized handwashing was needed in the removal of bacteria as well as preventing the spread of it. In the same study, nurses also said handwashing was instinctive rather than thoughtful. The result of the study would suggest that despite the differences in age, the field of employment, and scientific training, all three groups viewed handwashing as being essential in protecting their health and demonstrated that the attitude towards handwashing is developed early in childhood and continued into adulthood (Whitby et al., 2006). If this result holds true for this ABHSs study, one would expect there would be no differences in the number of times a person would use ABHSs despite differences in age as well as employment.

\section{Role of culture/religion/ethnicity in hand hygiene compliance}

According to Allegranzi, Memish, Donaldson, \& Pittet (2009), attitude toward hand hygiene is believed to be deeply influenced by cultural and religious factors. Some religions stipulate dirty hands must be washed with water, thus providing a barrier to the use of ABHSs. In some religions, the prohibition of alcohol will be a hindrance to the use of ABHSs. For example, the Islamic tradition forbids the drinking and use of alcohol and the Sikh religion considers alcohol use as a sin or is thought to cause mental impairment (Allegrazi et al, 2009). Culture can also influence a person's hygienic practices. For example in certain African countries, the hand must be washed before placing anything on one's lips. There are also differences in interpreting when a hand is visibly dirty. Blood or other contaminants will be difficult to see on the hands of a dark skinned person, suggesting there may be an ethnic difference in how often one washes their hands (Allegrazi et al, 2009). Taking culture, religion, and ethnicity into account, if the premises from Allegranzi et al. 
are true, one can expect a difference in hand hygiene practices with the various groups.

\section{Role of Environmental Health Officers with ABHSs}

In Canada there are no legislations governing the use of ABHSs in institutions; the Food and Drug Act and its regulations only stipulate the labelling requirements of these antiseptics. CDC has a guideline- Guidelines for Hand Hygiene in Healthcare Settings, 2002, and WHO has a guideline - Guideline on Hand Hygiene in Healthcare, 2009, that institutions can refer to when setting up their hand hygiene protocols. With a lack of legislations pertaining to where ABHSs can be placed and how it can be used, Environmental Health Officers (EHOs) must undertake a consulting role with respect to ABHSs. EHOs can work with institutions in designing outbreak response protocols to protect staff members and the institution's vulnerable patrons.

\section{Research question}

The primary goal of this research project was to gain a better understanding of the level of knowledge from the general population regarding ABHSs efficacy and compare this with the level of knowledge from health professionals. The secondary goal of this project was to determine whether factors such as income, gender, age, culture, religion, ethnicity, and educational level impact knowledge.

\section{METHODS AND MATERIALS}

\section{Description of materials used}

This study was conducted via a self-administered survey. In order to improve the validity of the survey and to reach a larger audience, an online survey and a paper survey were created to gather data from the population.

Survey Monkey (2014) was used to create the online survey. Facebook, a social media platform that shares information on the internet, was used to distribute the survey. A paper copy of the survey with similar wording and questions was handed to respondents that did not have access to internet. Microsoft Excel was used to create charts and tables. Number Cruncher Statistical Systems (NCSS) - Version 9 was used to analyze for statistical significance. An invitation letter was used to invite participants to participate in the survey. A consent form was given describing the purpose of the study and obtaining consent from participants. A questionnaire was used to assess the public knowledge level regarding ABHS.

\section{Description of standard method}

When the online survey was created with Survey Monkey, respondents were given the option of selecting from a list of pre-set responses specified by the researcher or writing out their own responses. The survey included seven demographic questions, one question regarding the number of times the participant uses ABHS, one question regarding reasons why they did not use ABHS and ten knowledge questions. The demographic questions collected information such as the participant's age, gender, occupational field, individual income, highest level of education completed, ethnicity and religion. The knowledge questions included multiple choice questions regarding when ABHSs should be used, the most effective alcohol concentration, the mode of action of ABHS, and the minimum amount to be applied. The knowledge questions also included True or False questions regarding whether ABHSs contributed to antibiotic resistance, whether they are effective against antibiotic-resistant bacteria, whether they are effective against influenza virus and Norovirus, whether they can be absorbed into the skin and bloodstream and cause intoxication, and whether they are more effective than soap and water at killing pathogens. The knowledge questions were set out to evaluate the level of understanding from the general population and each of the knowledge questions had only one correct answer. The number of correct answers from each questionnaire was tabulated.

The survey link was posted on the researcher's Facebook wall with a request to the researcher's contacts to complete the survey and re-post on their own Facebook wall so that their contacts can complete it. Another post was made on the researcher's wall two weeks after the initial one to thank the respondents and remind them to repost it. This second post also served to target contacts that may have missed it the first time.

To test the knowledge of the elderly population who may not have access to computers or may not be computer-literate, paper copies of the same questionnaire were delivered to the participating senior home, Seton Villa, located on 3755 McGill St, Burnaby. The results were 
analyzed with the statistical tools built into NCSS and tested against a significance level of 0.05 .

In creation of the questionnaire, questions asking sensitive information such as income and religion were given the option of "I would rather not answer".

\section{Reliability and validity of measures}

According to Merriam-Webster's online dictionary, reliability means "the extent to which an experiment, test, or measuring procedure yields the same results on repeated trials" (2013). This study used close-ended questions in the questionnaire; this minimized the amount of interpretation errors and increased reliability. Another way to increase reliability of surveys was to ask similar questions differently at the beginning and the end of the survey; if the respondents entered similar answers, the results of the survey can be considered reliable. By sending the survey to the same participants that participated in the pilot study and observing if the answers were similar, the surveys' reliability was also increased.

Validity of a survey means that the survey is measuring what it is intended to measure. Internal validity is how well the results of a study can lead to an accurate conclusion about the cause and effect. External validity is the ability of the survey to extrapolate the results to the general population (Heacock \& Sidhu, 2013). With the inherent participant biases from online surveys, external validity can only be achieved if a more representative sample can be obtained. To increase both the reliability and validity of the survey, the questionnaires were previewed by the BCIT instructors and a pilot study was conducted in January of 2014. Unfortunately for questionnaires, variables such as misunderstanding a question and not answering truthfully will always exist. Hence, the best approach is to make the questions as clear as possible and to specify to each participant that their identify will remain anonymous, that participation is voluntary, and that the survey can be terminated by the respondent at any time without penalty.

\section{Inclusion and exclusion criteria}

All age groups were welcome to participate in the study. Having a large pool of potential responders helped to approximate a representative sample of the population and improves the validity of the responses. People that selected "I do not consent to participate in this survey" were excluded from the data analysis.

\section{Ethical consideration}

A consent form was attached to the questionnaire stating the purpose and nature of the study. The consent form stated that participation in the study was voluntary and individual responses would be kept confidential. No name would be revealed to any persons other than the researcher for the purpose of the prize draws. To obtain permission to include the elderly population, a phone call, email, or personal visit was made to the senior homes explaining the purpose of the study and permission was obtained prior to delivery of the questionnaires. The researcher and the supervisor's contact information were provided if respondents had concerns or questions about the ethics of the study. The survey received ethics approval from supervisors at BCIT.

\section{Pilot studies}

A pilot study was conducted in January of 2014. The purpose of the pilot study was to assess: 1 ) Whether the wording of the questions was clear to the respondents. 2) Whether any of the questions were offensive. 3) The amount of time required to complete the survey. 4) The difficulties encountered in the completion of the survey.

\section{STATISTICAL ANALYSIS}

\section{Description of the data}

The data collected included multichotomous nominal data (religion, ethnicity, occupational field, gender and reasons for not using hand sanitizers), ordinal data (level of education completed, age and income), and numerical data (number of ABHS applications per day and number of correct answers by each individual).

\section{Descriptive statistics}

Excel bar graphs were used to display the average knowledge scores from each of the demographic categories such as religion, ethnicity, occupational field, gender, highest level of education completed, age, and individual income. Excel bar graphs were also used to display the number of ABHS applications per day reported by the respondents and the reasons why they chose not to use ABHSs. The range of knowledge score was 8 (lowest was one, highest 
was nine). The standard deviation of the knowledge score was 1.88 .

\section{Inferential statistics}

Independent samples T-test was used to assess whether gender had an effect on the knowledge score regarding ABHSs. Knowledge scores from participants that selected "Other" in the gender category were excluded. One-way ANOVA was used to assess whether factors such as religion, ethnicity, highest level of education completed, age, individual income or occupational field had an effect on the respondent's knowledge regarding the efficacy of ABHS.

\section{Statistical package used}

The statistical package used to analyze the study data is NCSS - Version 9.

\section{Results}

Descriptive Analysis

85 participants completed the survey, 72 via Survey Monkey and 13 via paper surveys. The summary table of analysis is provided in Table 1. For gender, the average knowledge score from males (6.42) was higher than females (5.19).

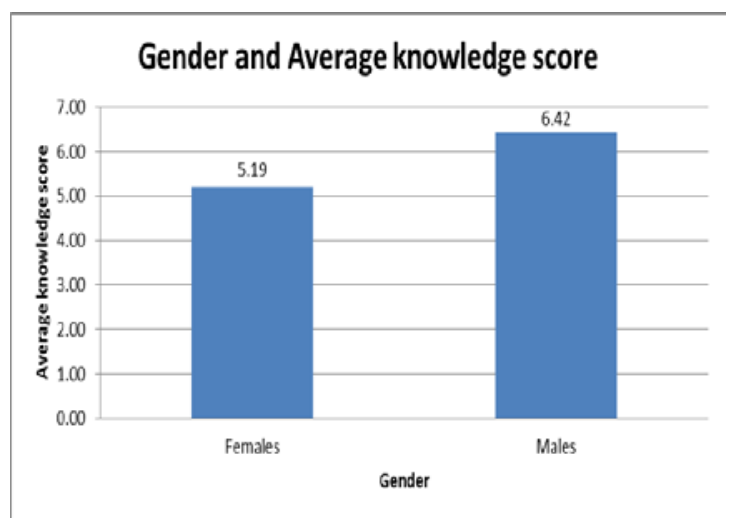

Figure 1: Gender and Average knowledge score

For age, the average knowledge score from respondents that were less than 29 years of age was the highest (5.98) while respondents that were greater than 40 years of age had the lowest average knowledge score at 4.11.

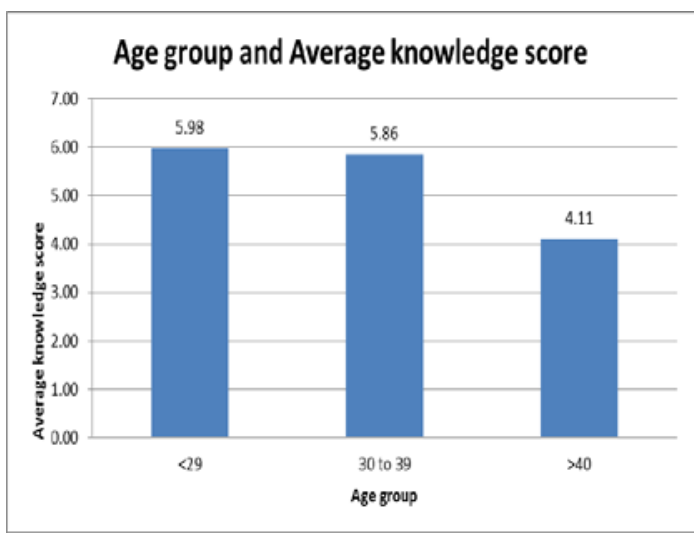

Figure 2: Age and Average knowledge score

For highest level of education completed, the respondents who had some graduate school education or completed graduate school had the highest average knowledge score (7.00) while respondents that had high school graduation or less had the lowest average knowledge score (4.14).

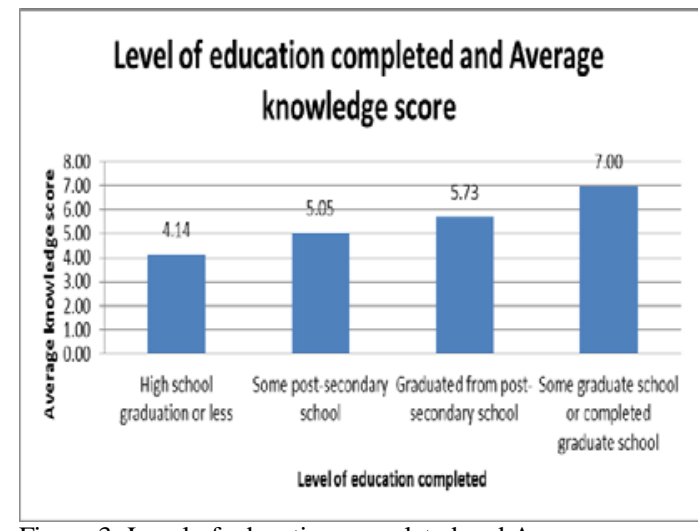

Figure 3: Level of education completed and Average knowledge score

For individual income, the respondents whose income was greater than $\$ 60,000$ had a higher average knowledge score than those with lower income.

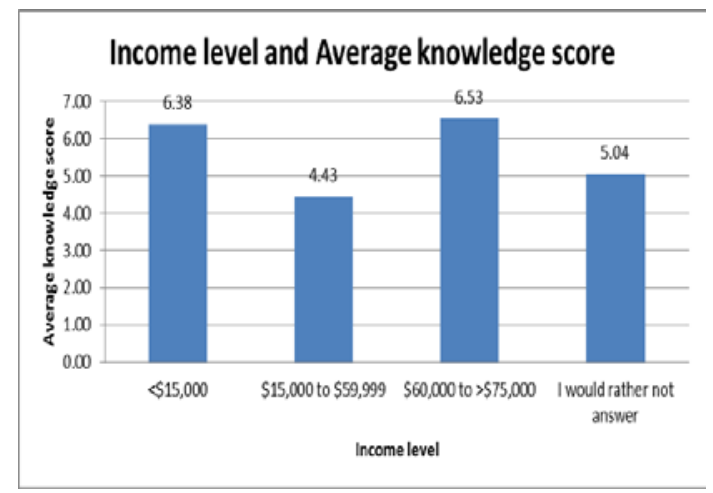

Figure 4: Income level and Average knowledge score 
For occupational field, the respondents in the health-related professions had a higher average knowledge score (6.19) than respondents who were in non-health related professions (5.59).

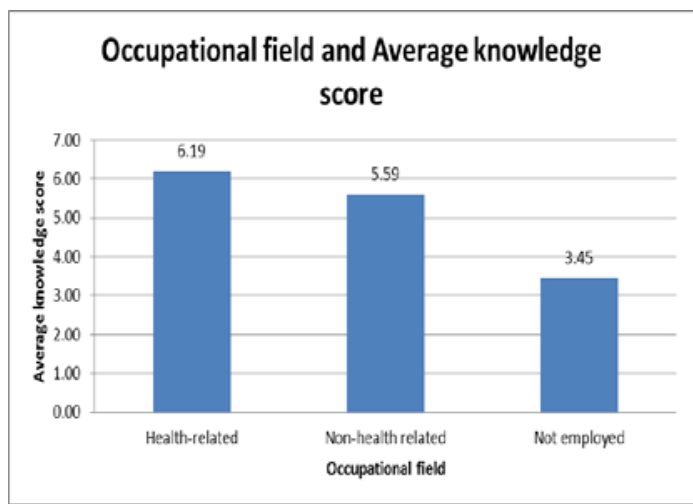

Figure 5: Occupation and Average knowledge score

For religion, the respondents that were nonreligious had higher average knowledge score (6.14) than respondents who identified themselves with Christianity or other religions, 4.97 and 5.13 respectively.

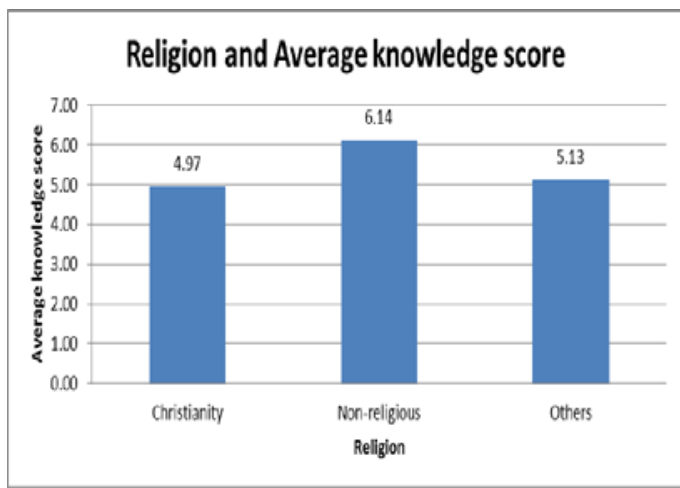

Figure 6: Religion and Average knowledge score

For ethnicity, there was no statistically significant difference in the average knowledge scores among the groups that responded.

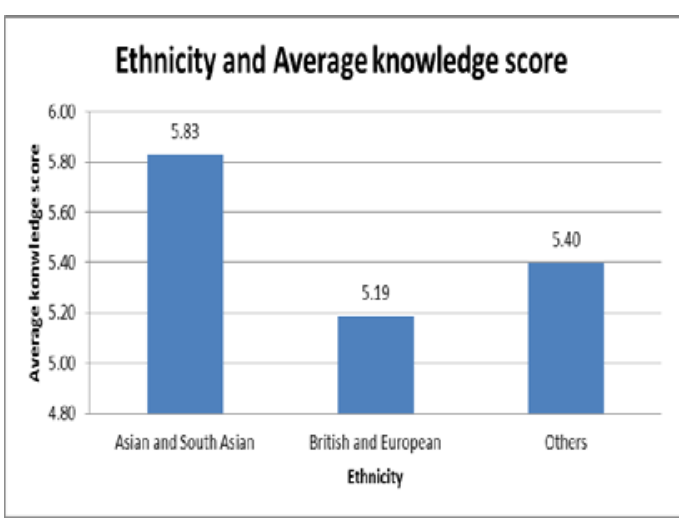

Figure 7: Ethnicity and Average knowledge score

Inferential Analysis

\begin{tabular}{|l|l|l|l|l|}
\hline Variable(s) & Null hypothesis & $\begin{array}{l}\text { Test used, } \\
\text { P value, } \\
\text { Decision }\end{array}$ & $\begin{array}{l}\text { Power, } \boldsymbol{\alpha} \text { \& } \boldsymbol{\beta} \\
\text { error }\end{array}$ & $\begin{array}{l}\text { Comment regarding decision } \\
\text { at } \\
\boldsymbol{\alpha}=\mathbf{0 . 0 5}\end{array}$ \\
\hline Gender & $\begin{array}{l}\mu 1 \text { (female) }-\mu 2 \\
\text { (male) }=0\end{array}$ & $\begin{array}{l}\text { Two } \\
\text { samples T- } \\
\text { test } \\
\text { P = 0.00455, } \\
\text { Reject Ho }\end{array}$ & $\begin{array}{l}\text { Power }= \\
0.82191, \\
\text { No } \alpha \& \beta \text { error }\end{array}$ & $\begin{array}{l}\text { There is a statistically } \\
\text { significant difference in the } \\
\text { knowledge scores between the } \\
\text { genders. }\end{array}$ \\
& & & $\begin{array}{l}\text { Specifically the knowledge } \\
\text { score is higher in male } \\
\text { compared to females. }\end{array}$ \\
\hline
\end{tabular}




\begin{tabular}{|c|c|c|c|c|}
\hline Age & $\begin{array}{l}\mu 1(29 \text { or younger }) \\
=\mu 2(30 \text { to } 39)= \\
\mu 4(\text { Greater than } \\
40)\end{array}$ & $\begin{array}{l}\text { One-way } \\
\text { ANOVA } \\
\mathrm{P}= \\
0.002319 \\
\text { Reject Ho }\end{array}$ & No $\alpha \& \beta$ error & $\begin{array}{l}\text { There is a statistically } \\
\text { significant difference in the } \\
\text { knowledge scores between the } \\
\text { age groups. } \\
\text { Specifically the knowledge } \\
\text { scores from participants who } \\
\text { are less than } 29 \text { years of age } \\
\text { were different than the } \\
\text { knowledge scores from } \\
\text { participants who are } 40 \text { or } \\
\text { older. The knowledge scores } \\
\text { from participants who are } \\
\text { between } 30-39 \text { are different } \\
\text { than the knowledge scores } \\
\text { from participants who are } 40 \\
\text { or older. The knowledge } \\
\text { scores from participants who } \\
\text { are } 40 \text { or older are different } \\
\text { than the knowledge scores } \\
\text { from participants who are less } \\
\text { than } 29 \text { years of age and those } \\
\text { that are between } 30-39 \text {. }\end{array}$ \\
\hline $\begin{array}{l}\text { Highest } \\
\text { Level of } \\
\text { Education } \\
\text { Completed }\end{array}$ & $\begin{array}{l}\mu 1 \text { (High school } \\
\text { graduation or less) } \\
=\mu 2 \text { (Some post- } \\
\text { secondary school) }= \\
\mu 3 \text { (Graduated from } \\
\text { post-secondary } \\
\text { school) }=\mu 4 \text { (Some } \\
\text { graduate school or } \\
\text { completed graduate } \\
\text { school) }\end{array}$ & $\begin{array}{l}\text { One-way } \\
\text { ANOVA } \\
\mathrm{P}= \\
0.040742, \\
\text { Reject Ho at } \\
\alpha=0.05 \\
\\
\text { Do not reject } \\
\text { Ho at } \alpha= \\
0.01\end{array}$ & $\begin{array}{l}\text { Possible } \alpha \& \beta \\
\text { error }\end{array}$ & $\begin{array}{l}\text { At } \alpha=0.05 \text {, there is a } \\
\text { statistically significant } \\
\text { difference in the knowledge } \\
\text { scores between respondents } \\
\text { with different education levels } \\
\text { completed. Specifically } \\
\text { respondents that received some } \\
\text { graduate school education or } \\
\text { completed graduate school } \\
\text { differed from those who had } \\
\text { high school graduation or less. } \\
\text { At } \alpha=0.01 \text {, there is no } \\
\text { statistically significant } \\
\text { difference in the knowledge } \\
\text { scores between respondents } \\
\text { with different education levels } \\
\text { completed. }\end{array}$ \\
\hline $\begin{array}{l}\text { Personal } \\
\text { Income }\end{array}$ & $\begin{array}{l}\mu 1(<\$ 15,000)= \\
\mu 2(\$ 15,000 \text { to } \\
\$ 59,999)=\mu 3 \\
(>\$ 60,000)=\mu 4(I \\
\text { would rather not } \\
\text { answer })\end{array}$ & $\begin{array}{l}\text { One-way } \\
\text { ANOVA } \\
\mathrm{P}= \\
0.000162, \\
\text { Reject Ho at } \\
\alpha=0.05\end{array}$ & $\begin{array}{l}0.983379 \\
\text { No } \alpha \& \beta \text { error }\end{array}$ & $\begin{array}{l}\text { There is a statistically } \\
\text { significant difference in the } \\
\text { knowledge scores between } \\
\text { respondents of different } \\
\text { income categories. } \\
\text { Specifically those that said "I } \\
\text { would rather not answer" } \\
\text { scored differently than those } \\
\text { whose income is } \$ 60,000 \text { to } \\
>\$ 75,000 \text {, and differed from } \\
\text { those whose income is less } \\
\text { than } \$ 15,000 \text {. Respondents } \\
\text { whose income is between }\end{array}$ \\
\hline
\end{tabular}




\begin{tabular}{|c|c|c|c|c|}
\hline & & & & $\begin{array}{l}\$ 15,000 \text { to } \$ 59,999 \text { scored } \\
\text { differently than those whose } \\
\text { income is } \$ 60,000 \text { to } \\
>\$ 75,000 \text {, and differed from } \\
\text { those whose income is less } \\
\text { than } \$ 15,000 \text {. }\end{array}$ \\
\hline $\begin{array}{l}\text { Occupational } \\
\text { field }\end{array}$ & $\begin{array}{l}\mu 1 \text { (Health-related) } \\
=\mu 2 \text { (Non-health } \\
\text { related) }=\mu 3 \text { (Not } \\
\text { employed) }\end{array}$ & $\begin{array}{l}\text { One-way } \\
\text { ANOVA } \\
\mathrm{P}= \\
0.000060, \\
\text { Reject Ho at } \\
\alpha=0.05\end{array}$ & $\begin{array}{l}0.989327 \\
\text { No } \alpha \& \beta \text { error }\end{array}$ & $\begin{array}{l}\text { There is a statistically } \\
\text { significant difference in the } \\
\text { knowledge scores between the } \\
\text { respondents of different } \\
\text { occupational fields. } \\
\text { Specifically participants who } \\
\text { were in health-related } \\
\text { professions differed from those } \\
\text { who were not employed but } \\
\text { did not differ from those who } \\
\text { are non-health related. } \\
\text { Respondents that were non- } \\
\text { health related differed from } \\
\text { those who are not employed } \\
\text { but did not differ from those } \\
\text { who are in health-related } \\
\text { professions. }\end{array}$ \\
\hline Religion & $\begin{array}{l}\mu 1 \text { (Christianity) }= \\
\mu 2 \text { (Non-religious) } \\
=\mu 3 \text { (Other) }\end{array}$ & $\begin{array}{l}\text { One-way } \\
\text { ANOVA } \\
\mathrm{P} \\
=0.026181, \\
\text { Reject Ho at } \\
\alpha=0.05 \\
\\
\text { Do not reject } \\
\text { Ho at } \alpha= \\
0.01\end{array}$ & $\begin{array}{l}0.678020 \text { at } \alpha= \\
0.05 \\
0.431304 \text { at } \alpha= \\
0.01 \\
\text { Possible } \alpha \& \beta \\
\text { error }\end{array}$ & $\begin{array}{l}\text { At } \alpha=0.05 \text {, there is a } \\
\text { statistically significant } \\
\text { difference in the knowledge } \\
\text { scores between respondents in } \\
\text { different religions. } \\
\text { Specifically those who were } \\
\text { Christians differed in } \\
\text { knowledge score from those } \\
\text { who are non-religious. } \\
\text { At } \alpha=0.01 \text {, there is no } \\
\text { statistically significant } \\
\text { difference in the knowledge } \\
\text { scores between respondents in } \\
\text { different religions. }\end{array}$ \\
\hline Ethnicity & $\begin{array}{l}\mu 1 \text { (Asian and } \\
\text { South Asian) }=\mu 2 \\
\text { (British and } \\
\text { European) }=\mu 3 \\
\text { (Others) }\end{array}$ & $\begin{array}{l}\text { One-way } \\
\text { ANOVA } \\
\mathrm{P} \\
=0.441511, \\
\text { Do not reject } \\
\text { Ho at } \alpha= \\
0.05\end{array}$ & & $\begin{array}{l}\text { There is no statistically } \\
\text { significant difference in } \\
\text { knowledge scores between } \\
\text { respondents with different } \\
\text { ethnicities. }\end{array}$ \\
\hline
\end{tabular}

Table 1: Summary of analysis 


\section{DISCUSSION}

With the promotion of alcohol-based hand sanitizers from well-established health agencies, the availability and acceptance of these products grew rapidly. These products can be found in many institutions and are used by a variety of people. Whether the users truly understand the effectiveness and limitations of these products is uncertain. The following are the significant findings from this study.

Participants who were 40 years of age or higher had the lowest average knowledge scores. In particular, participants who were 70 or older had the lowest knowledge score of all age groups. This is also reflected by a number of responses from seniors when the researcher visited the senior home; many seniors refused to participate citing they could not answer the questions even if they had tried.

Another significant finding was that the level of education appeared to have an impact on the knowledge scores. Based on the results, the average knowledge score increased with increases in level of education completed.

When assessing the average number of ABHS applications per day from the respondents, 44 percent of the respondents answered "Never". When inquired about the reasons why they do not use ABHS, the number one answer, accounting for $57 \%$ of the responses, was "Soap and water are readily available".

Examining the answers to the individual questions, the responses for a few questions were surprising to the researcher. When asked whether ABHS contribute to antibiotic resistance, $43 \%$ of the respondents answered yes. This is in disagreement with scientific finding which suggested ABHS does not contribute to antibiotic resistance (Li, 2011; WHO, 2013). When asked what alcohol concentration is the most effective, $18 \%$ of respondents answered $<20 \%$ alcohol, $13 \%$ of respondents answered 20 to $39 \%$ and $28 \%$ of respondents answered $>95 \%$ while only $32 \%$ were able to answer correctly (60-95\% is the most effective). In a study by Yang (2011), the results of her study showed that $52 \%$ of participants were unable to correctly identify the proper ABHS concentration. This wide variation in responses suggested that the public does not seem to know what percentage of alcohol is most effective against germs. When asked whether ABHS is less effective than soap and water at killing germs, $56 \%$ of respondents said ABHS is less effective. This is in agreement with the study by Yang (2010) that concluded participants do not use ABHSs because they feel soap and water are more effective at removing bacteria as well as dirt and grease. When asked whether ABHSs are effective against Norovirus, $47 \%$ of the respondents answered yes. This result was concerning because scientific data has shown that ABHSs are not effective against Norovirus and the use of ABHS may actually contribute to the increase in the number of Norovirus outbreaks in institutions.

It is reassuring however to find that majority of respondents were able to correctly identify when ABHSs should be used, that ABHSs are effective against anti-biotic resistant bacteria, that ABHSs work by disrupting the germs' cell membrane, that ABHSs are effective against influenza virus, that a minimum of a dime sized portion of ABHS should be applied, and that ABHS cannot be absorbed into the bloodstream and cause intoxication to the user.

\section{RECOMMENDATIONS}

\section{To future studies:}

The first and most important recommendation is to get a large sample size. If future students wish to continue with alcohol-based hand sanitizer surveys and if budget allows, the student should look to work with a well-established survey company such as Angus Reid. This would allow the student to reach out to a wider demographic group.

The second recommendation is in regards to participation from seniors. The researcher should consider going to independent living facilities because it increases the chance that the residents are able to participate. The researcher can also go to community centers and arrange with the coordinator to make the completion of the survey as part of seniors' activities.

Although in-person surveys are more time consuming, they do generate higher response rates.

\section{To health professionals:}

The results of this survey revealed that the older population and people with lower education were lacking in knowledge regarding alcohol-based hand sanitizers. Public health professionals 
should act as educators in providing the knowledge and resources, they can hand out educational material to debunk the myths surrounding ABHS. Public health professionals can conduct informal presentations at institutions and long term care facilities regarding when to use ABHS, how to use them and what they are effective against. Public health professionals can also work with planners in institutions in designing a response protocol involving ABHS if an outbreak occurs.

\section{LIMITATIONS}

There were three major limitations to this study. The first limitation was the method of survey distribution. Distribution of the online survey through Facebook, although it did generate responses, the respondents were reflective of the demographic of the researcher's Facebook contacts. The majority of the respondents (60\%) were between the ages of $20-29,55 \%$ were Asian and South Asian and 60\% the respondents graduated from post-secondary school with a Diploma or Bachelor's Degree. This limited the generalizability of the study.

The second limitation was the number of responses. Due to the number of overall respondents (85), some categories (age, education, income, religion, and ethnicity) were forced to collapse in order to be analyzed using NCSS. This collapse in categories would affect the ability to pinpoint exactly which of the demographic group lacked knowledge regarding hand sanitizers.

The third limitation was the inability to obtain participation from the senior population. The researcher had visited and emailed over 15 senior homes in the Lower Mainland however only one independent living facility agreed to participate. A high percentage of the rejections from the coordinators of these facilities cited dementia, a common illness among the residents, as the reason for rejection.

\section{FUTURE RESEARCH SUGGESTSIONS}

The researcher came across research papers that discussed differences in hand hygiene practices with regards to demographic differences, however this was limited to handwashing. For this study the demographic differences were examined with regards to knowledge. If a future student wishes to conduct a survey on ABHS, they could conduct a study examining the association between demographic differences and ABHS usage rates.

Another suggestion is instead of conducting a survey on the general public, the researcher could reach out to caregivers in long term care facilities or in acute care facilities as these employees are most likely to be exposed to pathogens.

\section{ACKNOWLEDGEMENT}

The author thanks Ann Matthews from Seton Villa for arranging for in-person selfadministered surveys with seniors in her facility, and Denny Zheng and Radha Lochan for their assistance with the administration of the surveys.

\section{COMPETING INTERESTS}

The author declare that they have no competing interests involved in the research topic beyond the scope of this course.

\section{CONCLUSIONS}

The following are significant findings in this study: Respondents over the age of 40 , particularly the senior population, had the lowest average knowledge score. The level of education completed was an important predictor of average knowledge score. Respondents who had higher levels of education had higher average knowledge scores. Respondents in the health related fields scored higher than respondents that were in non-health related fields, although the difference was not significant. Ethnicity was not an important factor that affected the average knowledge score regarding ABHSs. When the public is not using ABHSs, they were still following proper hand hygiene by using soap and water. The majority of the respondents were knowledgeable of the fact that ABHSs are effective against influenza virus. Nearly half of the respondents thought ABHSs were effective against Norovirus, which is not the case (Rotter, 2001). 


\section{REFERENCES}

Allegranzi, B., Memish, Z. A., Donaldson, L., \& Pittet, D. (2009). Religion and culture: potential undercurrents influencing hand hygiene promotion in health care. American Journal of Infection Control. 37(1). 28-34. Retrieved from http://www.sciencedirect.com.ezproxy.librar y.ubc.ca/science/article/pii/S0196655308004 896\#

Bloomfield, S. F., Aiello, A. E., Cookson, B., O’Boyle, C., \& Larson, E. L. (2007). The effectiveness of hand hygiene procedures in reducing the risk of infections in home and community settings including handwashing and alcohol-based hand sanitizers. American Journal of Infection Control. 35(10), S27S64. Retrieved from http://www.ajicjournal.org/article/S01966553(07)00595-0/fulltext

Boyce, J. M. (2000). Using alcohol for hand antisepsis: Dispelling old myths. Infection Control and Hospital Epidemiology, 21(7). 438-441. Retrieved from http://www.jstor.org/stable/10.1086/501784

British Columbia Centre for Disease Control. (2012). Hand hygiene. Retrieved from http://www.bccdc.ca/prevention/HandHygien e/default.htm

Centers for Disease Control and Prevention, (2002). Guideline for hand hygiene in healthcare settings. Morbidity and Mortality Weekly Report, 51. Retrieved from http://www.cdc.gov/mmwr/PDF/rr/rr5116.pd $\mathrm{f}$

Centers for Disease Control and Prevention. (2007). Hand-washing recommendations to reduce disease transmission from animals in public settings. Morbidity and Mortality Weekly Report, 56. Retrieved from http://www.cdc.gov/mmwr/preview/mmwrht $\mathrm{ml} / \mathrm{rr} 5605 \mathrm{a} 4 . \mathrm{htm}$

CIPHI. (2008). Use of alcohol-based hand sanitizers in food establishments. Food Council News. 11(4). Retrieved from http://www.ciphp.ca/fcnews/pub/2008/food_ 2008_07.pdf

Heacock, H. \& Sidhu, B. (2013). ENVH 8400 Power point presentation slides. British
Columbia Institute of Technology, Burnaby, BC.

Hintze, J. (2013). NCSS 9. NCSS, LLC. Kaysville, Utah, USA. www.ncss.com

Jabbar, U., Leischner, J., Kasper, D., Gerber, R., Sambol, S. P., Parada, J. P., Johnson, S., \& Gerding, D. N. (2010). Effectiveness of alcohol-based hand rubs for removal of Clostridium difficile spores from hands. Infection Control and Hospital Epidemiology. 31(6). 565-570. Retrieved from http://www.jstor.org/stable/10.1086/652772

Li, R., (2011). Alcohol-based hand sanitizer safety. Retrieved from http://dpic.org/article/professional/alcoholbased-hand-sanitizer-safety

Liu, P., Yuen, Y., Hsiao, H., Jaykus, L., \& Moe, C. (2010). Effectiveness of liquid soap and hand sanitizer against Norwalk virus on contaminated hands. Applied and Environmental Microbiology. 76(2). Retrieved from http://aem.asm.org/content/76/2/394.full

Maryland Poison Center. (2007). The facts about hand sanitizers. Retrieved from http://mdpoison.com/education/pdf/Hand\%20 Sanitizer\%20MPC_03-12.pdf

Microsoft. (2010). Microsoft Excel. Redmond, Washington: Microsoft.

Ohio Department of Health. (n.d.). Facts about the use of alcohol-based hand sanitizers in Ohio schools. Retrieved from http://www.odh.ohio.gov/ /media/ODH/ASS ETS/Files/eh/school\%20environmental\%20h ealth/alcoholbasedhandsanitizerfactsheet.ashx

Pickering, A. J., Davis, J., \& Boehm, A. B. (2011). Efficacy of alcohol-based hand sanitizer on hands soiled with dirt and cooking oil. Journal of Water and Health, 9(3), 432. Retrieved from http://woods.stanford.edu/sites/default/files/fi les/HandSanitizer.pdf

Reliability. (2013). In Merriam-Webster online. Retrieved from http://www.merriamwebster.com/dictionary/reliability 
Reynolds, S.A., Levy, F., \& Walker, E.S., (2006). Hand sanitizer alert. Emerging Infectious Diseases. 12(3). 527-529. Retrieved from http://www.ncbi.nlm.nih.gov/pmc/articles/P MC3291447/

Rotter, M.L., (2001). Arguments for alcoholic hand disinfection. Journal of Hospital Infection, 48, S4-S8. Retrieved from http://0www.sciencedirect.com.innopac.lib.bcit.ca/sc ience/article/pii/S0195670101900040\#

Scott, E., \& Vanick, K. (2007). A survey of hand hygiene practices on a residential college campus. American Journal of Infection Control. 35(10). 694-696. Retrieved from http://www.sciencedirect.com.ezproxy.librar y.ubc.ca/science/article/pii/S0196655307004 580

Survey Monkey. (2014). What is your knowledge level regarding alcohol-based hand sanitizers. Last accessed: February 18, 2014. Retrieved from: https://www.surveymonkey.com/s/VBNSDY Z

Whitby, M., McLaws, M. L., Ross, M. W. (2006). Why healthcare workers don't wash their hands: A behavioural explanation. Infection Control and Hospital Epidemiology.
27(5). 484-492. Retrieved from http://www.jstor.org.ezproxy.library.ubc.ca/st able/10.1086/503335

WHO. (2013). Alcohol-based handrub risks/hazards. Retrieved from http://www.who.int/gpsc/tools/faqs/abhr2/en/ index.html

Widmer, A. F. (2000). Replace hand washing with use of a waterless alcohol hand rub. Clinical Infectious Diseases. 31(1), 136-143. Retrieved from http://cid.oxfordjournals.org/content/31/1/13 6.full

Wilson, J. H. (2005). Essential statistics. Upper Saddle River, New Jersey: Prentice Hall

Yang, C. (2010). The myth behind hand sanitizers: Risks associated with improper use of hand sanitizers in the public. BCIT, Burnaby BC.

Zimmerman, R. (2011). Alcohol-based hand sanitizers associated with norovirus outbreaks. Medscape Medical News. Retrieved from http://www.medscape.com/viewarticle/73788 4 